Article

\title{
Analysis of Research Topics and Scientific Collaborations in Renewable Energy Using Community Detection
}

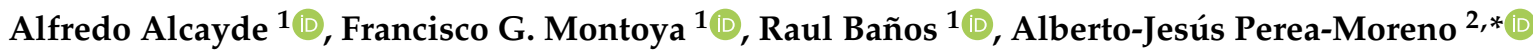 \\ and Francisco Manzano-Agugliaro ${ }^{1}$ (D) \\ 1 Department of Engineering, University of Almeria, ceiA3, 04120 Almeria, Spain; aalcayde@ual.es (A.A.); \\ pagilm@ual.es (F.G.M.); rbanos@ual.es (R.B.); fmanzano@ual.es (F.M.-A.) \\ 2 Departamento de Física Aplicada, Universidad de Córdoba, ceiA3, Campus de Rabanales, \\ 14071 Córdoba, Spain \\ * Correspondence: g12pemoa@uco.es; Tel.: +34-957-212-633
}

Received: 21 November 2018; Accepted: 27 November 2018; Published: 30 November 2018

\begin{abstract}
Renewable energy is a key breakthrough to mitigate carbon emissions, to reduce global warming, and for the creation of sustainable societies. Renewable energy is a broad area that includes different technologies that are being continuously improved to increase their efficiency and reduce cost. Many papers have been published in the last decades dealing with renewable energy issues, which is why it becomes important to determine the main topics of research, the main publications devoted to publishing scientific papers about renewable energy, and how researchers collaborate in this discipline. With these aims in view, this paper presents an advanced method for analysing publications about renewable energy and scientific collaboration networks in this field. This method is based on automatically obtaining bibliographic data from scientific publications through the use of the Scopus Database API Interface, which are then analysed using community detection algorithms and graph visualization software. The results obtained show that it is possible to determine the main areas of research activity as well as to identify the structures of the collaboration network in the field of renewable energy.
\end{abstract}

Keywords: renewable energy; sustainability; research activity; scientific collaborations; complex networks; community detection

\section{Introduction}

The worldwide consumption of primary energy in 2016 was assessed at 13,276.3 million Tonnes of Oil Equivalent (TOE) [1]. According to its origin, the consumption is distributed as follows, oil $4418.2(33.28 \%)$, natural gas $3204.1(24.13 \%)$, coal $3732.0(28.11 \%)$, nuclear energy $592.1(4.46 \%)$, hydroelectricity $910.3(6.86 \%)$, and renewable energy $419.6(3.16 \%)$. This dataset evidences that the contribution of renewable energy to the overall consumption is still low.

Renewable energy is a key breakthrough to mitigate carbon emissions, to reduce global warming and for the creation of sustainable societies. The main renewable energy sources and their energy conversion or usage forms are solar (photovoltaic and thermal power generation and water heaters), wind (power generation, wind generators, windmills, and water pumps), modern biomass (heat and power generation, pyrolysis, gasification, and anaerobic digestion), geothermal (urban heating, power generation, hydrothermal, and hot dry rock), ocean (tidal and wave power). Hydropower in rivers is often included in the group of renewable energies, although it often requires large infrastructures (dams) with negative environmental effects at a local level [2]. While the technological advances in 
hydropower generation have not been very significant in the last years given the maturity of this technology, other renewable energies, such as photovoltaic, wind, and biomass have had a considerable development thanks to the technological innovation [3]. On the other hand, geothermal energy, tidal, and wave power still require 31 important technological developments to be economically profitable. In addition, the study of renewable energies is often associated with a multitude of facets that are not only in the strict field of energy generation, but also key aspects such as energy saving, the conservation or storage of this energy, or the integration of distributed generation from renewable energy sources [4].

Renewable energies can be used as "raw materials" to produce hydrogen. The implementation of hydrogen as an energy source is another of the solutions along with renewable energies. This is known as "the hydrogen economy", a term currently used to refer to the alternative economic model to the use of fossil fuels mainly to be used in transportation $[5,6]$. This chemical element, as an energy vector, will revolutionize the immediate future. The technology used to obtain hydrogen has been developed for approximately three centuries, but it has been since the last few decades that it has been projected as a viable solution to the world's energy problems and to the environmental problems caused by the oil economy. Hydrogen as a fuel can be used in different ways: to generate electricity or to generate movement in internal combustion engines; in the market there are several alternatives to cars that use fossil fuels and instead use hydrogen as an energy source [7-10].

Renewable energy generation does not alter the thermal balance of the Earth or generate irretrievable waste, and the speed of its consumption does not exceed the speed of regeneration of the energy source and the raw material used in it. Historically, renewable energy technologies and costs of production involved that renewable energy projects typically came with a relatively low internal rate of return. But it must be clarified that these costs are internal to the energy system and do not consider external factors, including those environmental issues derived from the impact of exploitation of energy sources.

The promotion of renewable energy was largely neglected in the past, but nowadays it is one of the main pillars of the energy policy agenda in countries around the world [11]. In fact, policy support based on feed-in tariffs and feed-in premiums, together with fast decline in the costs of solar photovoltaic power and wind turbines in the last years, have allowed that solar and wind projects now become economically viable and adequate to repay project costs. There are important demographic and socioeconomic factors that determine the knowledge on different forms of renewable energy [12]. In any case, social acceptance of renewable energy [13] as a replacement for fossil fuels in electricity production should consider that for renewable technologies to continue growing their market share, they need to coexist with fossil fuel technologies [14]. In any case, it is important to promote efficient strategies to make renewable energy sources compatible with economic growth [15]. According to the United Nations (UN), sustainable energy is the main contributor to climate change and accounts for $\sim 60 \%$ of all global greenhouse gas emissions. Furthermore, the UN states that fossil fuels have long been the main source of electricity, generating large quantities of greenhouse gases [16]. In this sense, they recommend increasing the use of renewable energy sources for the creation of sustainable societies and even more so when electricity consumption is increasing rapidly.

Every year, prestigious international journals publish a large number of review articles with the aim of finding out about the technological innovations and research trends in the field of renewable energy. Most of these reviews focus on classifying and structurally listing the papers published so far. Other researchers have presented bibliometric studies about the publications retrieved from databases, such that bibliometric indicators are used as a tool for research performance evaluation. A major drawback of these indicators is that in the search for simplicity, important details are missed. Moreover, the volume of published research papers grows year after year at such a rate that the analysis of these publications has become a rather complex task.

This research fills an unexplored gap in the reviews of the field of renewable energy since it applies community detection algorithms to analyse the scientific publications in order to determine the most important areas of investigation in renewable energy, as well as to highlight the existing 
worldwide relationships between researchers. As a prerequisite for carrying out the study, it has been determined that it is necessary to make use of a reference database that allows an exhaustive analysis of all published papers in a wide interval of time. In particular, it is argued that it is possible to obtain detailed information on existing publications in the field of renewable energies retrieved from the Scopus database and to use community detection algorithms and graph visualisation tools to know with a high level of detail and in a very intuitive way which are the existing lines of research, as well as the networks of scientific collaborations around the world.

Some bibliometric studies dealing with renewable energy have been presented [17,18], but to our knowledge, none of them have investigated the whole network of publications about renewable energy in order to identify neither the areas of interest of the scientific community nor the scientific collaboration networks. For this reason, the novelty of the proposed study comes from the fact that all the published scientific work on renewable energies is analysed, while at the same time community detection techniques are applied to scientifically establish which are the groupings or clusters to classify these studies. This may make it possible to find areas of cooperation that have not yet been consolidated and that need to be covered from a scientific point of view. The originality of this study consists in identifying the gaps or scientific needs of the problem studied, which is the relationship between the works published on renewable energies, since these are of great relevance in our society. Once the possible gaps or improvements are detected as a result of this analysis, we will contribute in terms of knowledge and applicability, opening new fields of study for researchers specialised in energy.

The aim of this work is to analyse all the world scientific publications of renewable energy indexed in the Scopus database in order to study the most important areas of investigation in renewable energy, as well as to highlight the existing worldwide relationships between researchers and institutions. An important question here is how to analyse networks of publications and coauthorship in networks having thousands of nodes. Having in mind that a common feature of scientific collaboration networks is their complexity as well as the existence of internal structures or communities [19], community detection algorithms are applied. Community detection is an important problem that is based on the existence of groups of nodes within a largest network that are connected in a denser way than the rest of the nodes pertaining to the network [20]. Therefore, the nodes that belong to the same community have a greater connectivity and a higher probability of presenting similar characteristics, i.e., the nodes of a given community would have special relationships [21].

The rest of the paper is organisesed as follows. Section 2 describes the methodology of the study, including how to retrieve information from Scopus using the Scopus Database API Interface. Section 3 presents the results obtained from the Scopus database and discusses the utility of community detection to analyse a large volume of publications. The main conclusions of this research are provided in Section 4.

\section{Materials and Methods}

Scopus and Web of Science are multidisciplinary abstract and citation indexes providing useful information on papers published on journals, books, and conferences. Web of Science (WoS) was created in 1960, while Scopus was introduced by Elsevier in 2004, although it covers publications from 1996 [22]. The coverage between the two databases has been deeply studied, as well as the features and citation analysis capabilities of Scopus and WoS. In fact, the coverage of journals in Scopus is slightly higher (20,346 journals) than in WoS (13,605 journals) [23], with high correlations between the measures obtained with both databases for the number of papers, the number of citations received by countries, and their ranks. Previous bibliometric studies have also used the Scopus database to retrieve information about renewable energy [24].

\subsection{Retrieving Information Using Automated Scripts}

In order to retrieve and analyse those publications indexed in the Scopus database related to renewable energy, data extraction has been automatised by implementing specific software. 
This software bot, called Research Network Bot (ResNetBot), perform queries to obtain records (articles, authors, and institutions) using the Scopus Database API Interface [25]. The operation of ResNetBot can be divided into three phases (Figure 1): (1) Retrieving information about all the documents containing 'renewable energy' in the title or keywords. With this information, it constructs a graph where nodes represent publications and edges between two nodes indicate one of them cites the other one. (2) Retrieving information of all the authors of the papers processed in step (1), including the unique author identification number provided by Scopus, affiliations, publications and dates, number of citations, and h-index. (3) Construct the collaboration network by considering the authors that have published any paper containing 'renewable energy' in the title or keywords. For all authors information is stored about the number of author-coauthor collaborations and the affiliations, city, and country of these colleagues. This information is used to construct a graph where nodes represent the researchers and edges between two nodes indicate they have coauthored (collaborated in) at least one paper.

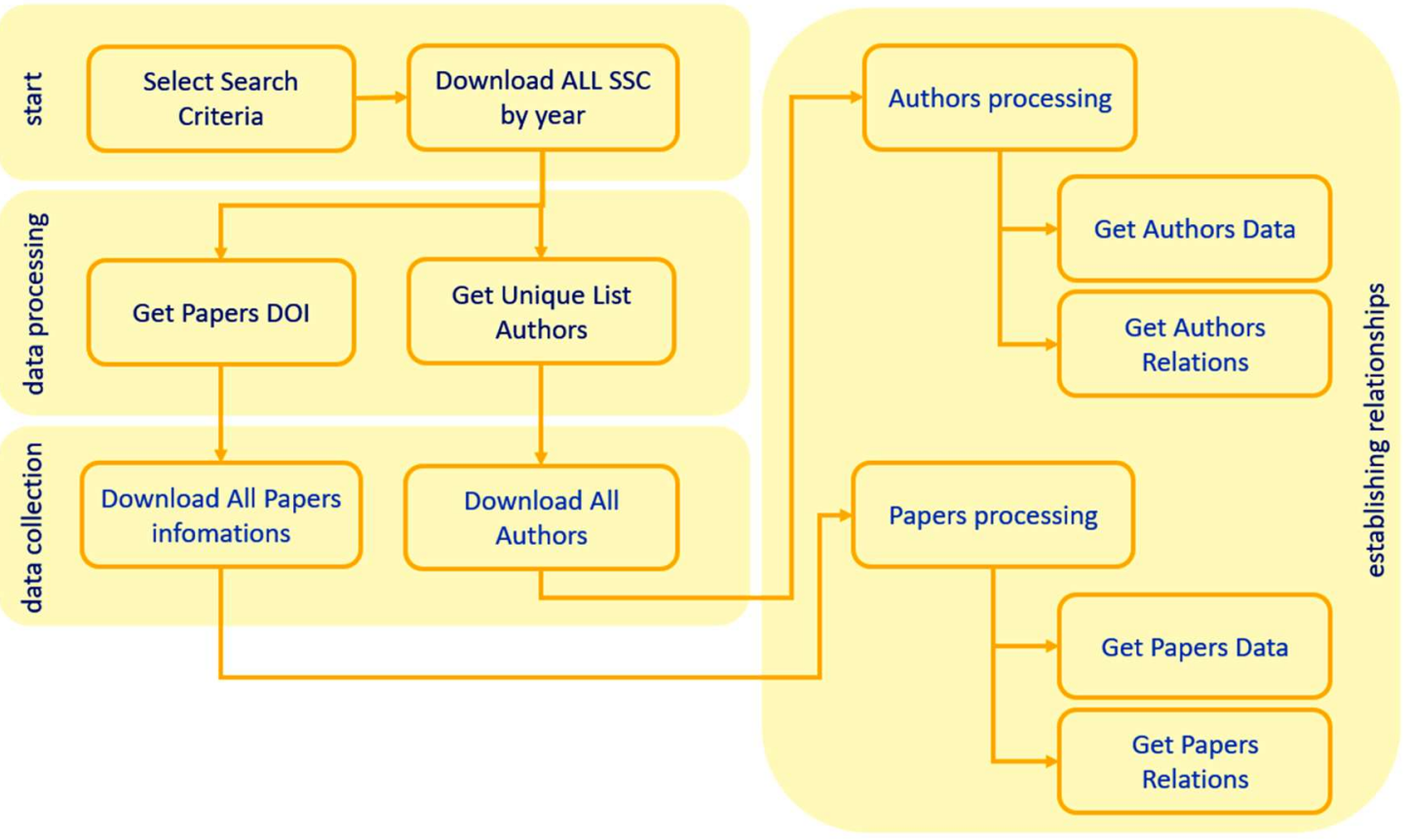

Figure 1. Scheme of ResNetBot operation.

The retrieved data was structured according to the corresponding fields and stored as a set of plain-text files using the JSON format [26]. It is usual to find inconsistencies in large databases that contain a huge amount of information from a variety of sources [27]. For example, when inspecting the keywords from publications, expressions with the same meaning can be written in different manners, e.g., 'Renewable energy' or 'Renewable energies'. To overcome these inconsistencies, ResNetBot applies different refinement algorithms from the OpenRefine software [28]. Finally, they are used spreadsheets to organise the refined information and identify unique values.

\subsection{Community Detection}

All complex systems share a common characteristic: community structures [29]. Communities consist of groups of nodes inside a network that are more densely connected with each other than with the remaining nodes of the network. As the nodes belonging to the same community have a higher likelihood of interaction, detecting those communities can reveal characteristics or functional relationships in a given network. Community detection is an important problem that is based on the existence of groups of nodes within the largest network that are connected in a denser way than the rest of the nodes pertaining to the network [20]. Therefore, the nodes that belong to the same community have a greater connectivity and a higher probability of presenting similar characteristics, i.e., the nodes 
of a given community would have special relationships [21]. Therefore, the community detection problem consists of partitioning the nodes into groups such that there are many edges connecting nodes within the same group, and comparatively few edges connecting nodes in different groups [29].

Research communities can be detected using community detection methods to group authors, journals, etc., with the aim of identifying patterns of community interactions [30]. In our case, it is considered that the nodes are publications, while edges represent that one of these papers has cited to the other one, such that the communities would represent groups of papers that often cite papers of the same community [19]. Other option is to consider that the nodes are researchers, while edges represent that two researchers have coauthored one or several papers, such that communities would represent groups of researchers that collaborate more frequently with each other [31]. This is particularly interesting considering that there is an increasing tendency across scientific disciplines to write multi-authored papers [32] such that the average number of coauthors per paper gradually increases [33]. This implies an increasing degree of scientific cooperation, that could be due to several reasons, e.g., many investigations requires the participation of different specialists of the same or different disciplines and the use of high-cost scientific equipment from several institutions.

Having in mind that a common feature of scientific collaboration networks is their complexity as well as the existence of internal structures or communities [19], community detection algorithms are applied. Most optimisation methods often apply modularity to detect communities in networks. Modularity [34] is the most extensively applied objective function in community detection due to its simplicity and ease of calculation. Modularity provides a numerical value that represents the quality of the solution, such that the greater the value is, the more accurate the community structure.

\subsection{Comparison with Other Approaches}

Although tens of thousands of review articles have been published in different fields of research, only a few studies have analysed the possibilities offered using community detection techniques for analysing and visualizing citation networks [30,35]. However, from the analysis of the existing publications in Scopus, it is possible to conclude that the use of these methods for detecting communities of authors and identifying research topics related to renewable energies has not been investigated, but almost all publications on this subject correspond to standard bibliometric studies. For example, a past paper [36] presented a systematic literature review to identify and evaluate the current state of knowledge on the drivers and barriers of countries' decision-making processes related to renewable energy deployment using. With this aim, these authors performed manual searches using different search terms and applying filters such as the years of publication or language. As result, a total of 60 academic manuscripts from Science Direct, JSTOR, and Google Scholar where included in this review. In another previous work [37], the authors presented a bibliometric analysis that allowed the identification of key concepts used in scientific literature on the integration of variable renewable energy into power networks using the Scopus database. Scopus has also been used by other researchers to review the literature related to the diffusion of profitable renewable energy businesses [38]. Other studies have recently reviewed the literature in the intersection of renewable energies and politics [39], which included a total of 853 publications retrieved from a systematic review by searching in WoS the papers with the words "renewable energy" and "politics" or "renewable energy policies" between 1998 and 2017.

In summary, when comparing the model proposed here with other review articles on different topics in the field of renewable energy recently published, it is observed that the latter focus on systematic reviews from searches in specialised databases, while our method is significantly more advanced since it incorporates two considerable improvements: the extraction of data is automatic using the ResNetBot software; the thousands of publications obtained by ResNetBot are classified using community detection algorithms and graph visualization tools (Gephi). 


\section{Results and Discussion}

The query performed in Scopus by end of 2017 about 'renewable energy' returned 24,152 records for documents, which were coauthored by 46,741 researchers from 23,092 different affiliations of 156 countries. In order to inspect these large numbers of publications, the query used Gephi [40], one of the most widely used graph visualization tools. Gephi is open source and allows to study in detail the characteristics of the network graphs by using multiple features, such as modifying the colour or size of vertices according some customised criteria, includes statistical metrics to define topological and relational characteristics among vertices. Moreover, Gephi includes community detection algorithms based on modularity.

Figure 2 shows the graph representing the documents about renewable energy. From the viewpoint of the connectivity, these publications can be classified into two groups: those belonging to the inner subnetwork (11,714 documents), and those that have no connection with the inner documents (12,438 documents). It is clarified that isolated nodes or groups located in the outer circle neither cite to the inner documents nor are cited by the latter ones. Probably, most of these nodes (papers) belonging to the outer circle include 'renewable energy' in their title or keywords, but they inspect this topic superficially, then including a few references about renewable energy that are not in the inner subnetwork.

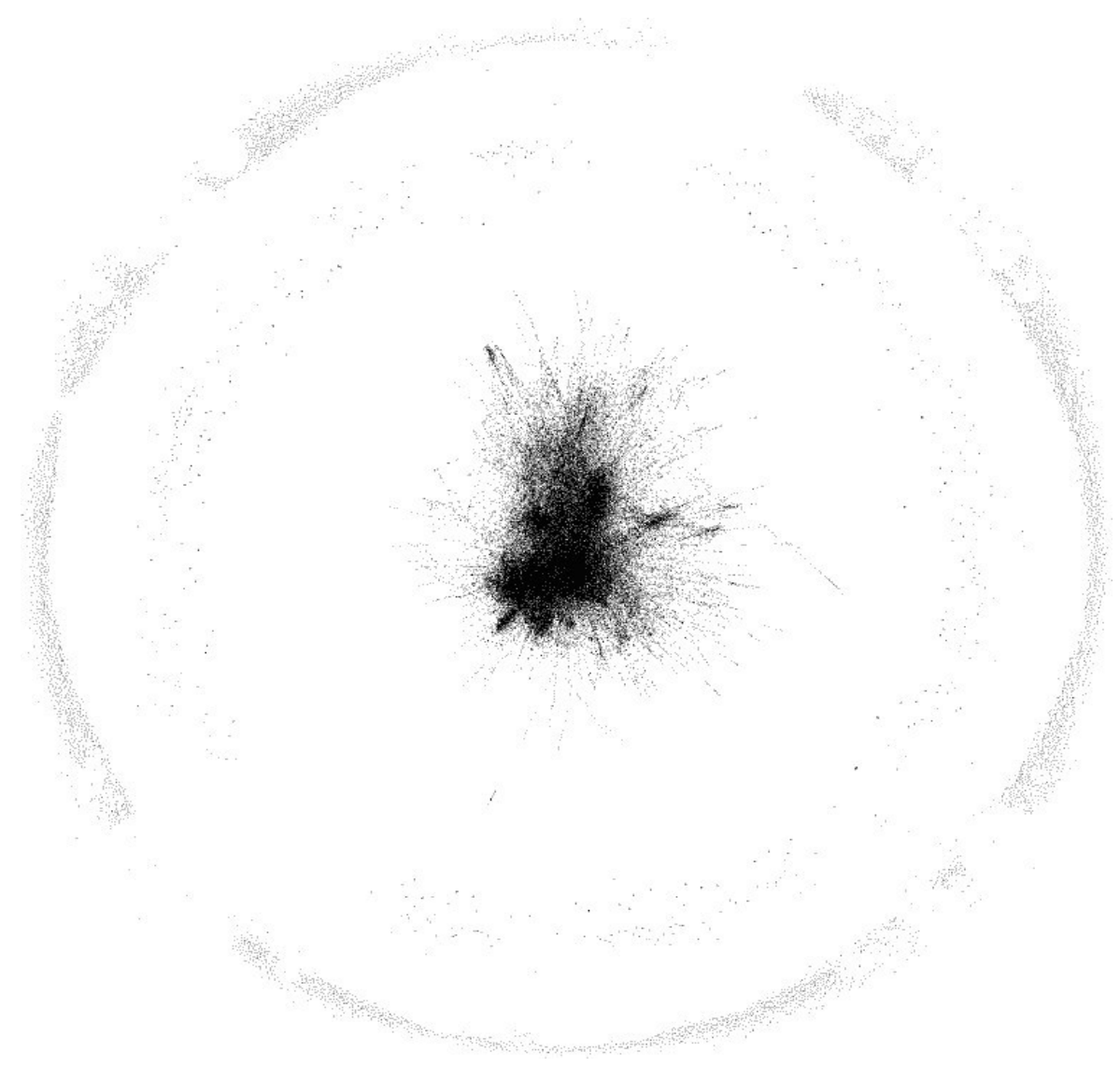

Figure 2. Network structure of documents related to renewable energy indexed by Scopus.

This section may be divided by subheadings. It should provide a concise and precise description of the experimental results, their interpretation as well as the experimental conclusions that can be drawn. 


\subsection{Trending Topics in Renewable Energy}

An important goal of this investigation is to determine the trending topics in renewable energy. This is not straightforward given the large number of articles of different topics. Fortunately, keywords allow to unveil general topics because authors usually include those that contain relevant words or phrases to allocate their publication to the subjects that they consider more appropriate [41].

If one was to pay attention to the 11,714 inner documents, the community detection reveals 32 communities, which are highlighted using different colours in Figure 3. The most used keywords included in the 10 major communities labelled in this figure are listed in Table 1, where communities are identified with a descriptive title and the 15 most common keywords. The main communities detected are: Hybrid systems, Electric vehicle and storage, Policy regulations, Distributed generation in smart grid, Sustainability, Usage in data centres, Economic issues or Econometrics, Biomass, Marine and ocean, and Water desalination. Contrary to what one might think, there are no specific communities regarding solar or wind, but they are cross-cutting issues in several communities. Another of the most relevant aspects of this methodology is to examine the proximity between certain scientific communities, as example between Distributed generation in smart grid and Hybrid systems. Regarding sustainability research, indicate that it is found near two other areas such as Economic issues and Policy regulations. On the other hand, it can be noted that some communities are somewhat separate from the rest, which suggests that they are authors who may come from different areas of work and are therefore not yet integrated into the core, for example Water desalination, Usage in data centres or Econometrics. This highlights that these areas are open to research or cooperation by those involved in other related research areas.

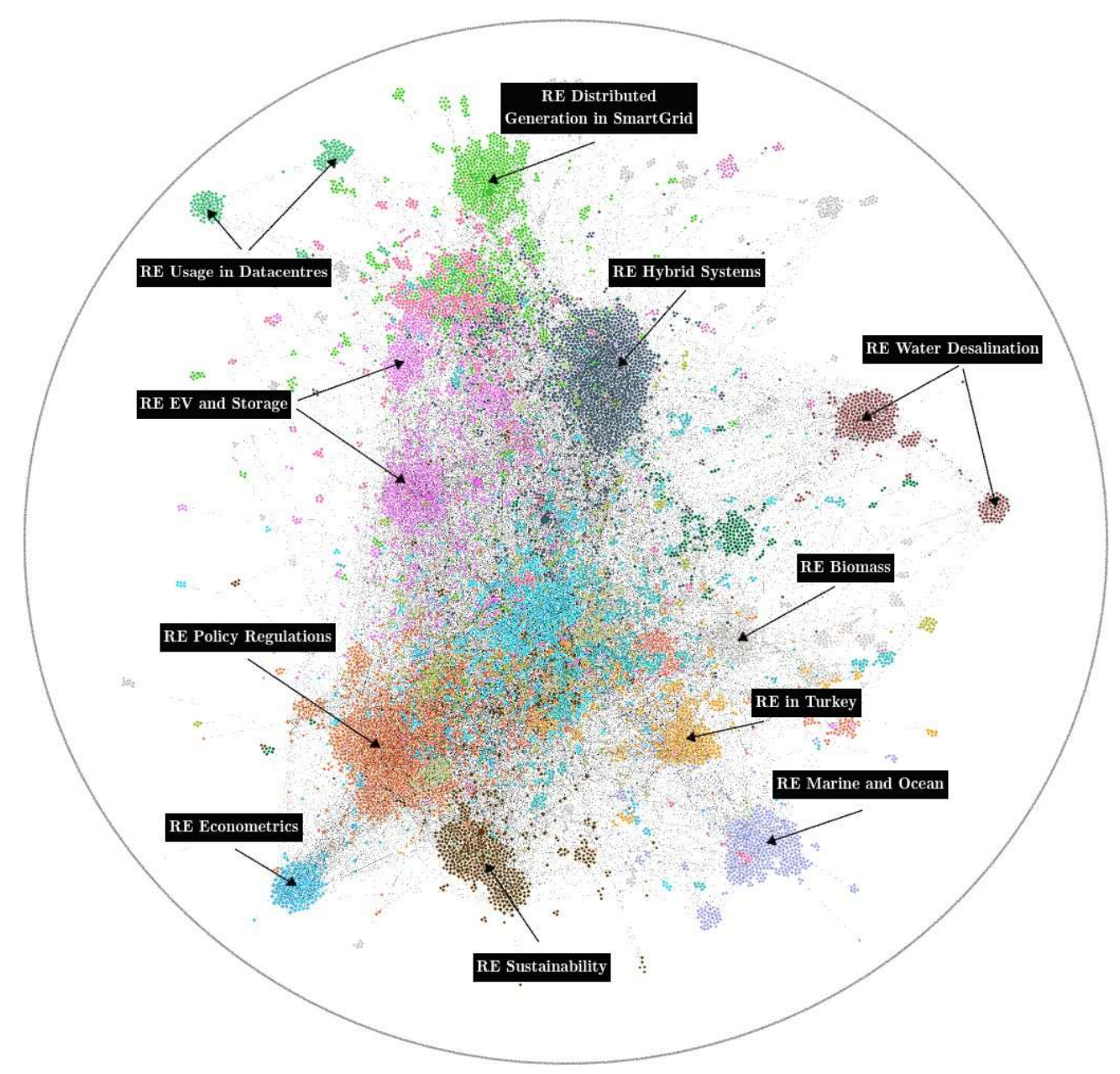

Figure 3. Community detection applied to the connected network of publications in renewable energy. 
Table 1. Most common keywords of the ten largest communities detected.

\begin{tabular}{|c|c|c|c|c|c|c|c|c|c|c|}
\hline & Hybrid Systems & Electric Vehicle & Policy Regulations & $\begin{array}{l}\text { Distributed Smart } \\
\text { Grid Generation in }\end{array}$ & Sustainability & $\begin{array}{l}\text { Usage in Data } \\
\text { Centres }\end{array}$ & Economic Issues & Biomass & Marine and Ocean & Water Desalination \\
\hline 1 & Optimization & Smart grid & Feed-in tariff & Microgrid & Willingness to pay & Data center & Economic growth & Biomass & Wave energy & Desalination \\
\hline 2 & Microgrid & Energy storage & Energy policy & Distributed generation & $\begin{array}{c}\text { Sustainable } \\
\text { development }\end{array}$ & Smart grid & Granger causality & Gasification & Wave power & Reverse osmosis \\
\hline 3 & Fuel cell & Electric vehicle & Climate change & Smart grid & Energy policy & Energy efficiency & $\begin{array}{l}\text { Sustainable } \\
\text { development }\end{array}$ & Biodiesel & Tidal energy & Solar energy \\
\hline 4 & Hybrid system & Optimization & Energy efficiency & Energy storage & Social acceptance & Cloud computing & Biomass & Malaysia & Ocean energy & Photovoltaic \\
\hline 5 & Hydrogen & $\begin{array}{l}\text { Distributed } \\
\text { generation }\end{array}$ & $\begin{array}{l}\text { Renewable portfolio } \\
\text { standard }\end{array}$ & Power quality & Sustainability & $\begin{array}{c}\text { Power } \\
\text { management }\end{array}$ & $\mathrm{CO} 2$ emissions & Biogas & Tidal power & $\begin{array}{c}\text { Pressure retarded } \\
\text { osmosis }\end{array}$ \\
\hline 6 & HOMER & Microgrid & Real options & Optimization & Contingent valuation & $\begin{array}{c}\text { Green } \\
\text { communications }\end{array}$ & $\begin{array}{c}\text { Energy } \\
\text { consumption }\end{array}$ & Biofuels & $\begin{array}{l}\text { Environmental } \\
\text { impact }\end{array}$ & Wind energy \\
\hline 7 & Energy storage & District heating & Electricity & $\begin{array}{l}\text { Distributed generation } \\
\text { (DG) }\end{array}$ & Climate change & Microgrid & Nuclear energy & Palm oil & Offshore wind & $\begin{array}{l}\text { Salinity gradient } \\
\text { power }\end{array}$ \\
\hline 8 & $\begin{array}{l}\text { Distributed } \\
\text { generation }\end{array}$ & Demand response & Electricity market & Energy storage system & Energy transition & Energy storage & Energy efficiency & Energy efficiency & $\begin{array}{l}\text { Wave energy } \\
\text { converter }\end{array}$ & $\begin{array}{c}\text { Reverse } \\
\text { electrodialysis }\end{array}$ \\
\hline 9 & $\begin{array}{l}\text { Hybrid power } \\
\text { system }\end{array}$ & Energy efficiency & Innovation & Power electronics & Attitudes & Energy harvesting & Solar energy & $\begin{array}{l}\text { Anaerobic } \\
\text { digestion }\end{array}$ & Power generation & Wind power \\
\hline 10 & $\begin{array}{l}\text { Hybrid energy } \\
\text { system }\end{array}$ & $\begin{array}{l}\text { Energy system } \\
\text { analysis }\end{array}$ & China & Demand response & Community & Green computing & Growth & Energy policy & Hydropower & Solar pond \\
\hline 11 & Smart grid & $\begin{array}{l}\text { Demand side } \\
\text { management }\end{array}$ & Sustainability & Fuel cell & Energy efficiency & Scheduling & Panel cointegration & Feed-in tariff & $\begin{array}{l}\text { Environmental } \\
\text { impact assessment }\end{array}$ & Optimization \\
\hline 12 & Electrolyzer & Hydrogen & European Union & Power systems & Planning & Battery & China & Sustainability & $\begin{array}{l}\text { Wave energy } \\
\text { converters }\end{array}$ & Geothermal energy \\
\hline 13 & $\begin{array}{c}\text { Energy } \\
\text { management }\end{array}$ & Vehicle to grid & $\begin{array}{l}\text { Tradable green } \\
\text { certificates }\end{array}$ & $\begin{array}{l}\text { Battery energy storage } \\
\text { system }\end{array}$ & NIMBY & Sustainability & Panel data & Energy & $\begin{array}{l}\text { Offshore wind } \\
\text { energy }\end{array}$ & Seawater \\
\hline 14 & Simulation & Electricity market & Policy & DC-DC converter & Education & Cellular networks & Miscanthus & Pyrolysis & Climate change & Energy recovery \\
\hline 15 & Rural electrification & V2G & Germany & Battery & Participation & $\begin{array}{c}\text { Lyapunov } \\
\text { optimization }\end{array}$ & Trade & Hydrogen & Tidal & Brackish water \\
\hline
\end{tabular}




\subsection{Type of Publication}

Most of the retrieved documents were published in specialised journals or conference proceedings. Table 2 shows the top 15 journals that have published more articles including 'renewable energy' in the title or keywords. The percentages are calculated over the total number of articles published in journals.

Figure 4 shows the network structure of all papers published in journals, conference proceedings, etc. A zoom was made to a specific area for more detail. It is observed that the pink dots ('Renewable and Sustainable Energy Reviews') play a central role, maybe because this journal is focused on reviews and therefore are cited from all branches of renewable energies. Moreover, green dots ('Energy Policy'), light blue dots ('Renewable Energy'), orange dots ('Applied Energy'), and dark dots ('Energy') are also close together, probably because they have the same type of scope-more general compared to the other journals-and therefore they are very much at the core of the network.

Table 2. List of journals with more papers including 'renewable energy' in their title or keywords.

\begin{tabular}{lcc}
\hline \multicolumn{1}{c}{ Journal Name } & \# Papers & Quota (\%) \\
\hline Renewable and Sustainable Energy Reviews & 1300 & 9.35 \\
Renewable Energy & 885 & 6.37 \\
Energy Policy & 814 & 5.86 \\
Energy & 431 & 3.10 \\
Applied Energy & 335 & 2.41 \\
International Journal of Hydrogen Energy & 206 & 1.48 \\
Energy Conversion and Management & 195 & 1.40 \\
Biomass and Bioenergy & 117 & 0.84 \\
Journal of Cleaner Production & 110 & 0.79 \\
Energy Economics & 108 & 0.78 \\
Energy and Buildings & 102 & 0.73 \\
Energies & 95 & 0.68 \\
Desalination & 94 & 0.68 \\
Solar Energy & 87 & 0.63 \\
International Journal of Renewable Energy Research & 84 & 0.60 \\
\hline
\end{tabular}

On the other hand, Table 3 presents a similar ranking about the publications in conference proceedings. In general, the publications in conferences are more equally distributed than in journals, such that the first of them does not reach $4 \%$ of the total, whereas the three first journals constituted more than $5 \%$ of the total of journal publications in this topic. 


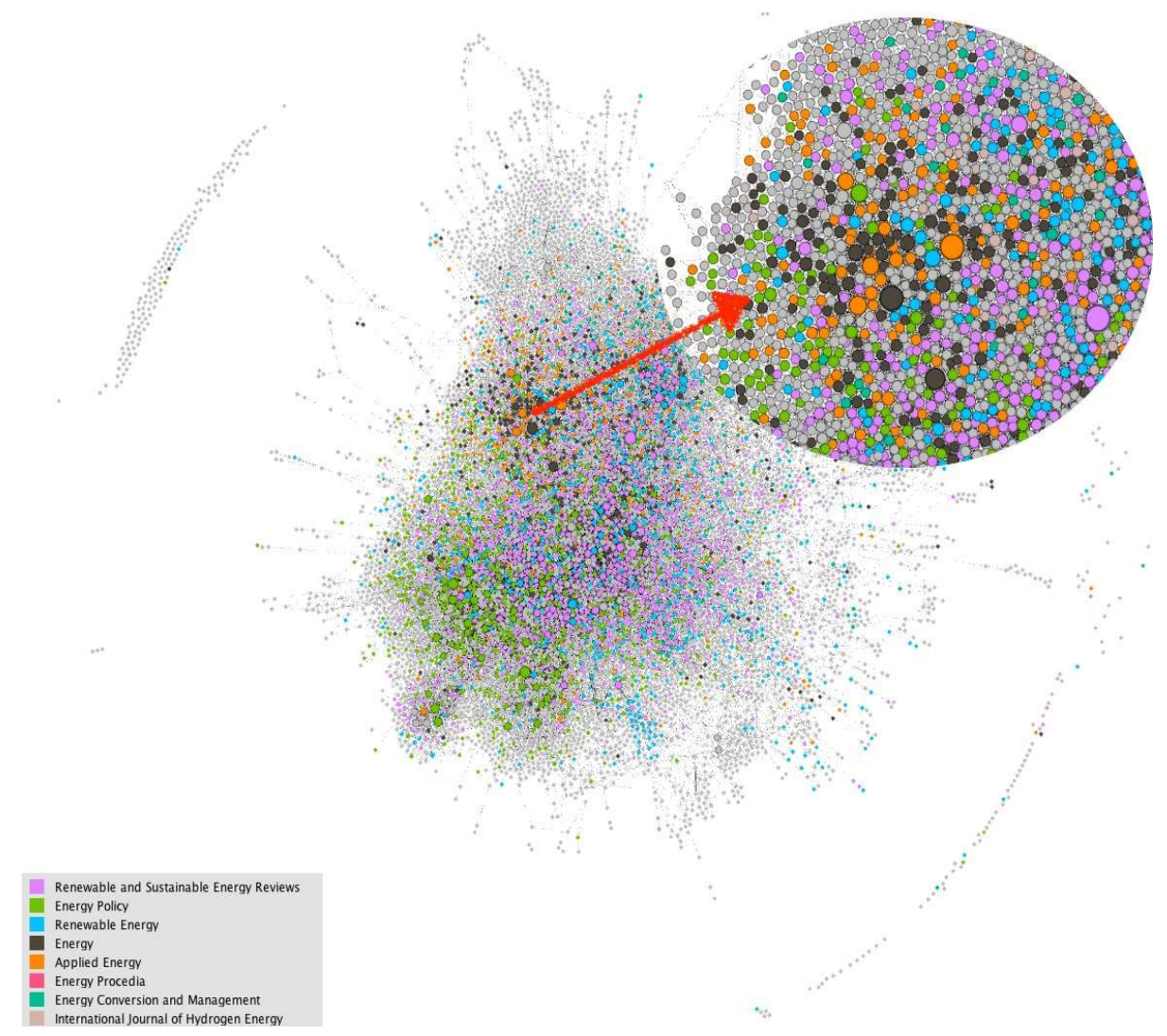

Figure 4. Most relevant journals in the field of renewable energy according to the number of papers including 'renewable energy' in the title or keywords.

Table 3. List of conference proceedings with more papers including 'renewable energy' in their title or keywords.

\begin{tabular}{lcc}
\hline \multicolumn{1}{c}{ Conference/Proceedings Name } & \# Papers & Quota (\%) \\
\hline Energy Procedia & 312 & 3.97 \\
IEEE Power and Energy Society General Meeting & 232 & 2.96 \\
IET Conference Publications & 123 & 1.57 \\
Proceedings of the Universities Power Engineering Conference & 96 & 1.22 \\
ASEE Annual Conference and Exposition Conference Proceedings & 93 & 1.18 \\
International Conference on the European Energy Market, EEM & 86 & 1.10 \\
IECON Proceedings (Industrial Electronics Conference) & 72 & 0.92 \\
World Renewable Energy Forum, WREF & 71 & 0.90 \\
IFAC Proceedings Volumes (IFAC-PapersOnline) & 69 & 0.88 \\
European Conference on Power Electronics and Applications, EPE-ECCE Europe & 63 & 0.80 \\
Asia-Pacific Power and Energy Engineering Conference, APPEEC & 61 & 0.78 \\
European Conference on Power Electronics and Applications, EPE & 61 & 0.78 \\
Procedia Engineering & 55 & 0.70 \\
International Conference on Renewable Energy Research and Applications, ICRERA & 52 & 0.66 \\
IEEE Energy Conversion, Congress and Exposition, ECCE & 49 & 0.62 \\
\hline
\end{tabular}

\subsection{Authors, Affiliations, and Countries in Renewable Energy}

Figure 5 shows the relationship between authors that have coauthored papers with 'renewable energy' in the title or keywords. In total, 46,471 authors are distributed in three layers: The outermost layer includes the authors who publish alone $(5.67 \%)$; the intermediate zone $(71.50 \%)$, where there are already collaborations between a few authors; and the inner layer $(22.83 \%)$ that constitutes the core of the network of scientific collaborations in renewable energy. 
Figure 6 shows the relationship between authors by countries (inner layer), where each colour indicates a country. It is observed that the scientific production in renewable energy is led by researchers affiliated to academic and research institutions from the United States $(12.6 \%)$, China (8.8\%), and United Kingdom (8.7\%). In the right part of the same figure the same network is represented disabling the parameter 'prevent overlap', i.e., the nodes can overlap each other. As expected, there are greater relationships between points of the same colour highlighting the collaboration between researchers from the same country (e.g., see large nodes in the left part of the Figure 6 representing researchers from the United States), and those of neighbouring countries (e.g., see the large nodes in the right part of the same figure representing researchers from Serbia close to those from Bosnia and Herzegovina, while other similar collaborations are observed between researchers from Italy and Greece and also France and Germany).

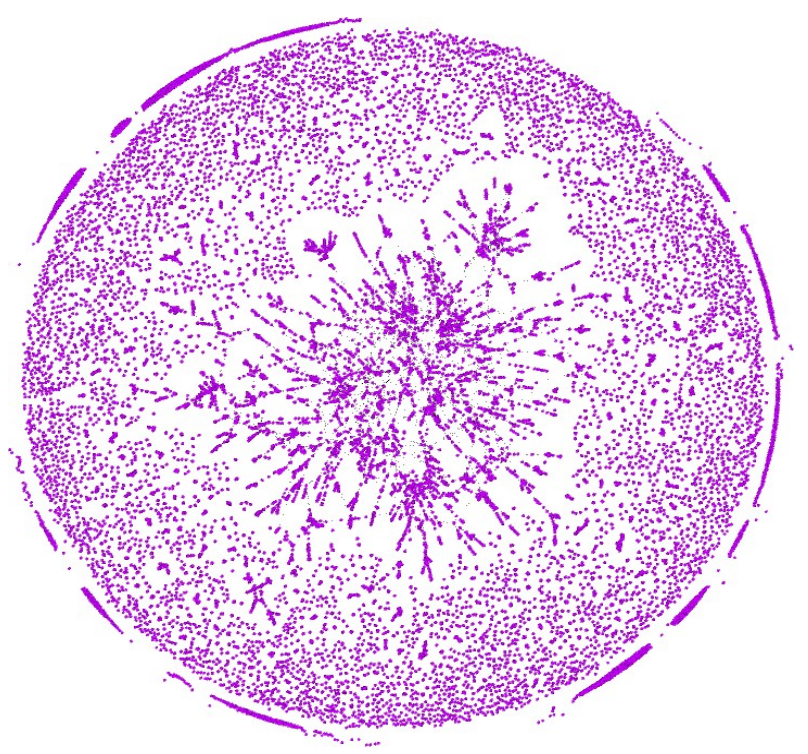

Figure 5. Network of collaborations of authors that have published papers containing 'renewable energy' in the title or keywords.
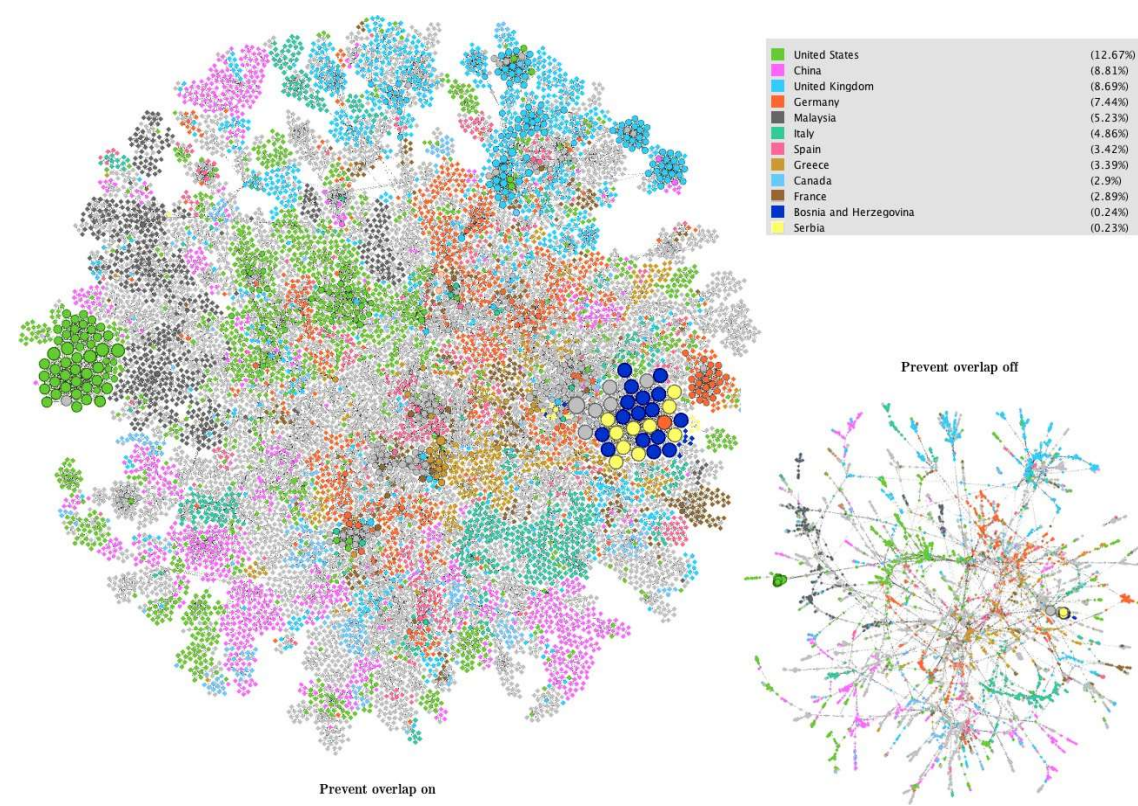

Figure 6. Collaborations among researchers from different countries. 
The proposed method is also used to analyse the scientific collaborations between the academic and research institutions of any country, and to determine which of them are more involved in renewable energy. Figure 7 shows the relationship between Chinese institutions, and Figure 8 displays the network of researchers affiliated with Chinese institutions, those having the largest number of researchers working on renewable energy are North China Electric Power University (7.15\%), Tsinghua University $(4.87 \%)$, and China Electric Power Research Institute (3.21\%). In these figures, authors with their eigenvector centrality (a measure of the influence of a node in a network) up to 0.05 are highlighted, such that they can be considered the leaders of this research field in China.

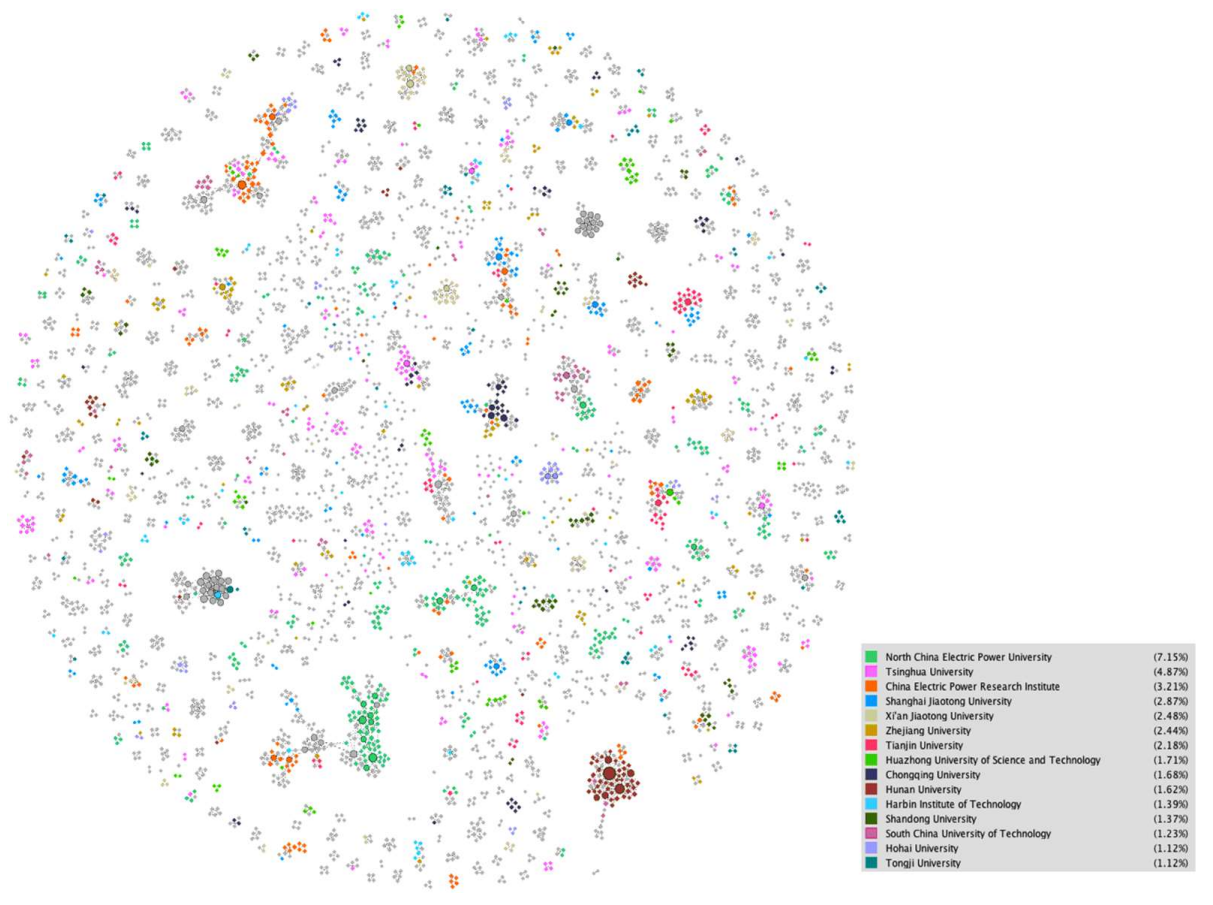

Figure 7. Relationship between Chinese institutions.

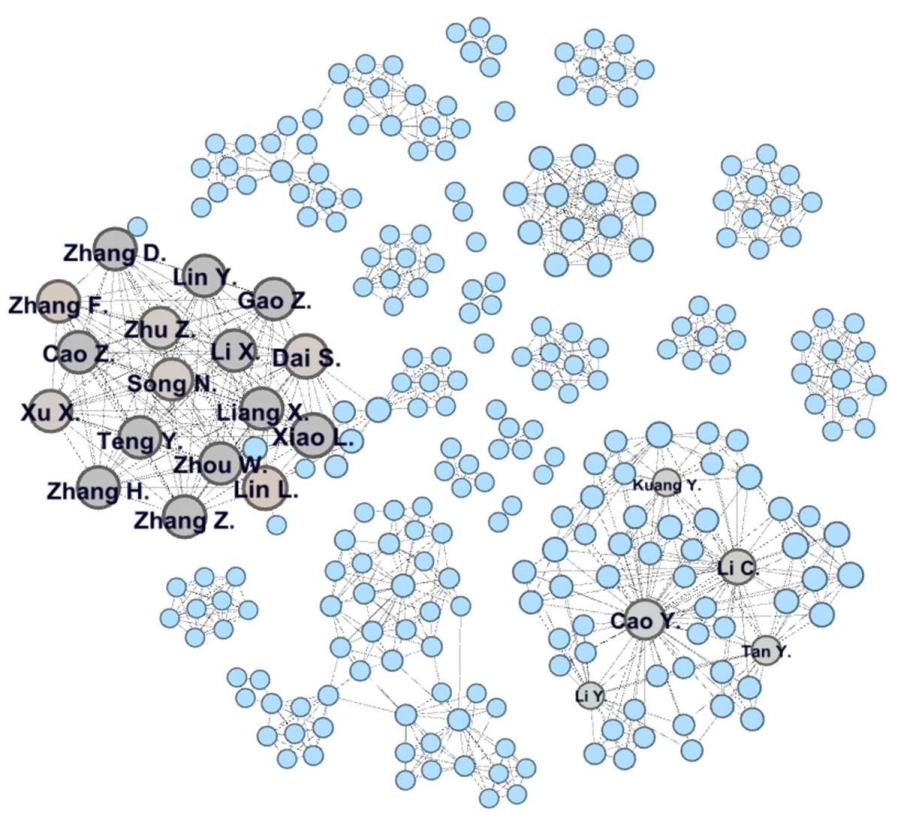

Figure 8. Relationship between authors from Chinese institutions. 
Following the example of China, Figure 9 shows the relationship between United States institutions and Figure 10 shows the collaboration network between researchers affiliated to institutions from the United States, such that the institutions with more researchers investigating in renewable energy are the National Renewable Energy Laboratory (3.36\%), Arizona State University $(1.31 \%)$, Cornell University (1.31\%), and Stanford University (1.31\%).

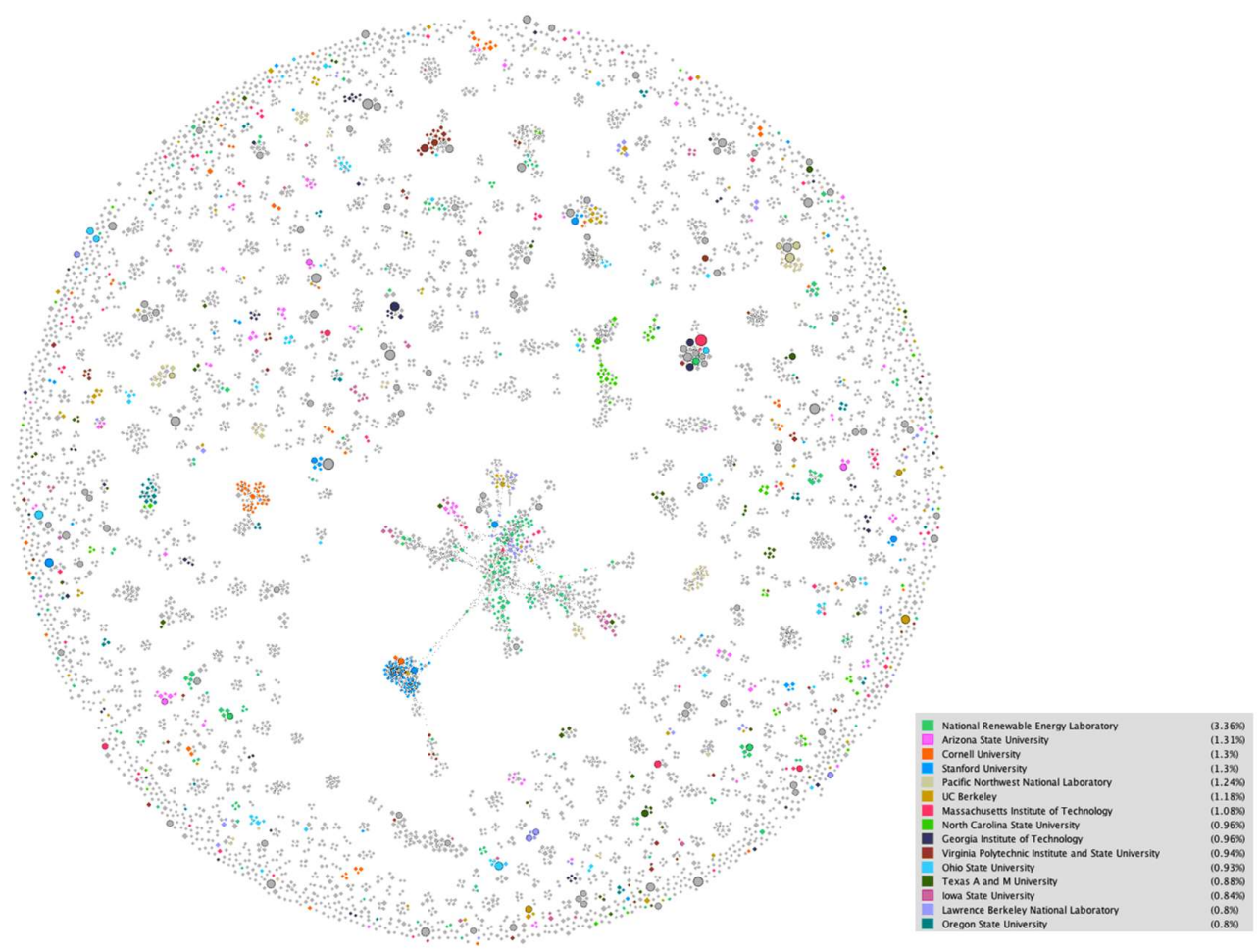

Figure 9. Relationship between US institutions.

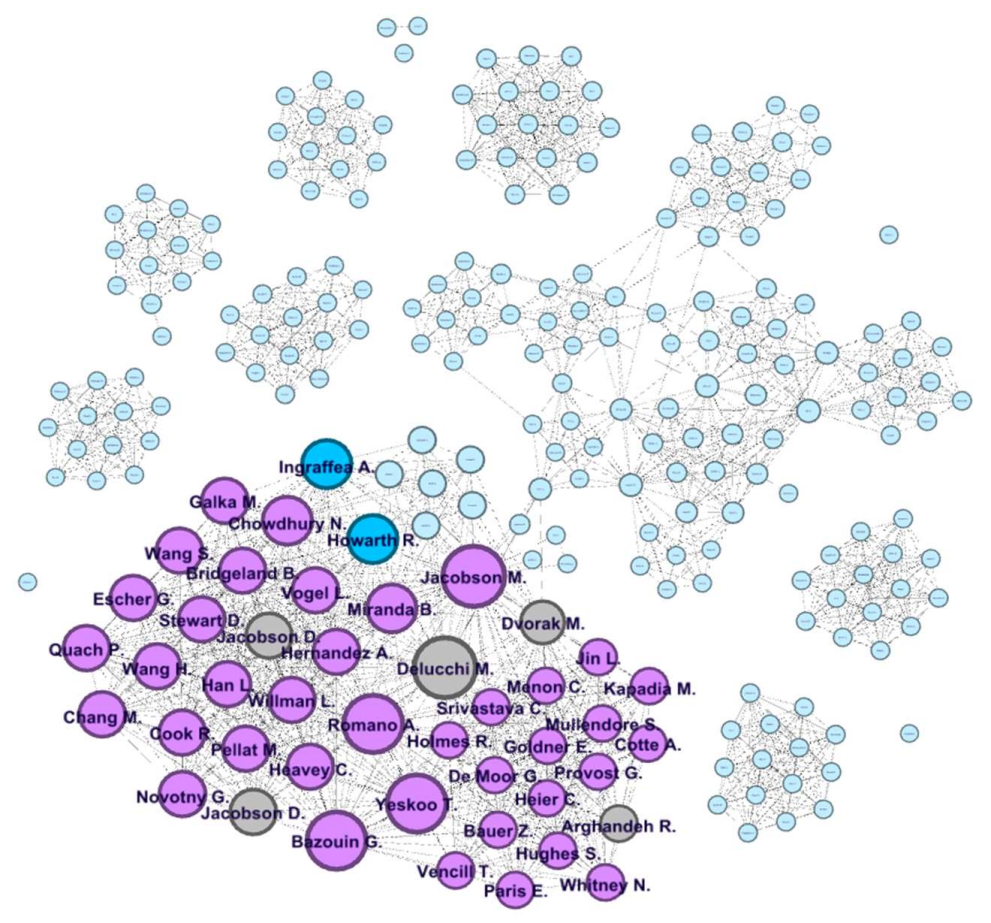

Figure 10. Relationship between authors from US institutions. 


\section{Conclusions}

Renewable energy sources can be exploited in a clean manner to obtain energy. Renewable energy is the future, and to get to that future it is necessary to invest in advanced technologies. But these technological advances come from the hand of the investigations performed by many researchers around the world. This paper presents a methodology to identify the topics of investigation in renewable energy, and to study how authors collaborate in this field. With this aim in mind, we provided a method to understand two complex systems: the network of publications according to the citations and the network of scientific collaborations according to the coauthorship of papers. For this purpose, a software bot has been used; it has retrieved data from all the publications indexed by Scopus containing 'renewable energy' in the title or keywords. This information is later used to analyse scientific collaboration networks of researchers working in this field. The novelty of this method comes from the fact that community detection algorithms are applied to study these networks. Thus, growing energy needs and the depletion of fossil fuel resources require research into sustainable energy options, including both renewable energy sources and sustainable storage technologies. The results obtained show that it is possible to determine some important areas of research activity, including hybrid systems, electric vehicle and storage, policy regulations, distributed generation in smart grid, sustainability, usage in data centres, economic issues, biomass, marine and ocean, and water desalination. Furthermore, the analysis of the collaboration network in the field of renewable energy has allowed to identify groups of researchers with different degrees of collaboration and to highlight the most important researchers and institutions investigating in renewable energy issues in different countries. In this study, the production of knowledge on the possibilities of improving renewable energies has been highlighted by means of scientific research focused towards certain fields of research that are large consumers of energy but are not yet fully integrated into the international scientific community through the relations between their researchers. So, the methodology used enables us to examine the relationships between communities, detecting those that are scientifically cooperating more deeply, such as distributed generation in smart grid and hybrid systems. It also illustrates the strong relationship between sustainability and research areas such as economics or legal regulations. It is worth highlighting those scientific areas or communities detected that are slightly separated from the rest, and therefore are not yet included in the core, emphasizing that these fields are open to research or cooperation of participants in other related research fields, such as water desalination or renewable energy use in data centres. An interesting conclusion is that the research of renewable energy as carbon neutral energy opens new perspectives for environmental and economic sustainability.

It has also been obtained information on journals and congresses that have published a higher number of papers on renewable energies. It is observed that the United States, China, the United Kingdom, Germany, and Malaysia are the countries with the highest number of authors affiliated to their universities and research centres who have published papers on renewable energies. It has also been obtained information on the journals and congresses that have published the largest number of papers on renewable energies.

As a limitation of the investigation, we must indicate that although there are community detection algorithms capable of satisfactorily processing graphs with thousands of nodes and edges, the graph visualization tools, as is the case of Gephi, show difficulties when processing and visualizing graphs with tens of thousands of nodes, so, if necessary, the study would be limited to those papers published in limited time intervals. Despite this limitation, this study contributes to the existing literature by suggesting a new approach to evaluate a large number of publications in renewable energy. In fact, to our knowledge, community detection algorithms have not yet been applied to obtain detailed information in review papers in engineering branches, including the field of renewable energy. The main contribution of this research lies in the fact that the methodology presented, supported by the results obtained, has great potential to know quickly and intuitively which are the main lines of research in renewable energy, the structure of collaborations of researchers interested in this subject, or to highlight the researchers with greater visibility in a given country or worldwide. In addition, 
the model presented can be extrapolated to the review of research work from any other scientific discipline, so it is suggested that those members of the scientific community interested in publishing review papers on any subject use the detection of communities in combination with graph visualization tools, as this can help them significantly improve the scope and impact of their research.

Finally, it should be noted that the results obtained from this bibliographic review using community detection algorithms and graph visualization tools can be very useful for agencies that fund research in the field of renewable energy can take into consideration the relationships between individual researchers, research groups, or organizations involved in projects. This opens new perspectives for improvement, not only for the scientific communities detected and far from the central nucleus of researchers, but also for those that do not appear given their current limited relevance. Therefore, this study can also be very useful for researchers to establish new collaborations with those groups and researchers of relevance in topics of interest.

Author Contributions: A.A. performed the literature review and article writing. R.B. and A.-J.P.-M. analysed the data using community detection methods. F.M.-A. and F.G.M.: Research idea, article writing, and formatting; they jointly contributed to the structure and aims of the manuscript, paper drafting, editing, and review. All authors have read and approved the final manuscript.

Funding: This research received no external funding.

Conflicts of Interest: The authors declare no conflicts of interest.

\section{References}

1. British-Petroleum. BP Statistical Review of World Energy 2016. 2017. Available online: http://www.bp. com/statisticalreview (accessed on 10 November 2018).

2. Manzano-Agugliaro, F.; Taher, M.; Zapata-Sierra, A.; Juaidi, A.; Montoya, F.G. An overview of research and energy evolution for small hydropower in Europe. Renew. Sustain. Energy Rev. 2017, 75, 476-489. [CrossRef]

3. Irandoustm, M. The renewable energy-growth nexus with carbon emissions and technological innovation: Evidence from the Nordic countries. Ecol. Indic. 2016, 69, 118-125. [CrossRef]

4. Abdmouleh, Z.; Gastli, A.; Ben-Brahim, L.; Haouari, M.; Al-Emadi, N.A. Review of optimization techniques applied for the integration of distributed generation from renewable energy sources. Renew. Energy 2017, 113, 266-280. [CrossRef]

5. Momirlan, M.; Veziroglu, T.N. The properties of hydrogen as fuel tomorrow in sustainable energy system for a cleaner planet. Int. J. Hydrog. Energy 2005, 30, 795-802. [CrossRef]

6. Kılkış, B.; Kılkış, Ş. Hydrogen Economy Model for Nearly Net-Zero Cities with Exergy Rationale and Energy-Water Nexus. Energies 2018, 11, 1226. [CrossRef]

7. Ajanovic, A.; Haas, R. Economic prospects and policy framework for hydrogen as fuel in the transport sector. Energy Policy 2018, 123, 280-288. [CrossRef]

8. Danilov, N.; Lyagaeva, J.; Vdovin, G.; Pikalova, E.; Medvedev, D. Electricity/hydrogen conversion by the means of a protonic ceramic electrolysis cell with $\mathrm{Nd} 2 \mathrm{NiO} 4+\Delta$-based oxygen electrode. Energy Conv. Manag. 2018, 172, 129-137. [CrossRef]

9. Rodríguez Matienzo, J.M. Influence of addition of hydrogen produced on board in the performance of a stationary diesel engine. Int. J. Hydrog. Energy 2018, 43, 17889-17897. [CrossRef]

10. Mazloomi, K.; Sulaiman, N.B.; Moayedi, H. Electrical efficiency of electrolytic hydrogen production. Int. J. Electrochem. Sci. 2012, 7, 3314-3326.

11. Fischer, C.; Greaker, M.; Rosendahl, K.E. Strategic technology policy as a supplement to renewable energy standards. Resour. Energy Econ. 2018, 51, 84-98. [CrossRef]

12. Karytsas, S.; Theodoropoulou, H. Socioeconomic and demographic factors that influence publics' awareness on the different forms of renewable energy sources. Renew. Energy 2014, 71, 480-485. [CrossRef]

13. Wüstenhagen, R.; Wolsink, M.; Bürer, M.J. Social acceptance of renewable energy innovation: An introduction to the concept. Energy Policy 2007, 35, 2683-2691. [CrossRef]

14. Blazquez, J.; Fuentes-Bracamontes, R.; Bollino, C.A.; Nezamuddin, N. The renewable energy policy Paradox. Renew. Sustain. Energy Rev. 2018, 82, 1-5. [CrossRef] 
15. Afonso, T.L.; Marques, A.C.; Fuinhas, J.A. Strategies to make renewable energy sources compatible with economic grow. Energy Strateg. Rev. 2017, 18, 121-126. [CrossRef]

16. Karunathilake, H.; Perera, P.; Ruparathna, R.; Hewage, K.; Sadiq, R. Renewable energy integration into community energy systems: A case study of new urban residential development. J. Clean. Prod. 2018, 173, 292-307. [CrossRef]

17. Baños, R.; Manzano-Agugliaro, F.; Montoya, F.G.; Gil, C.; Alcayde, A.; Gómez, J. Optimization methods applied to renewable and sustainable energy: A review. Renew. Sustain. Energy Rev. 2011, 15, 1753-1766. [CrossRef]

18. Iqbal, M.; Azam, M.; Naeem, M.; Khwaja, A.S.; Anpalagan, A. Optimization classification, algorithms and tools for renewable energy: A review. Renew. Sustain. Energy Rev. 2014, 39, 640-654. [CrossRef]

19. Newman, M.E. Coauthorship networks and patterns of scientific collaboration. Proc. Natl. Acad. Sci. USA 2004, 101, 5200-5205. [CrossRef] [PubMed]

20. Leskovec, J.; Lang, K.J.; Dasgupta, A.; Mahoney, M.W. Community structure in large networks: Natural cluster sizes and the absence of large well-defined clusters. Internet Math. 2009, 6, 29-123. [CrossRef]

21. Tang, L.; Liu, H. Community detection and mining in social media. Synth. Lect. Data Min. Knowl. Discov. 2010, 2, 1-137. [CrossRef]

22. Chadegani, A.A.; Salehi, H.; Yunus, M.M.; Farhadi, H.; Fooladi, M.; Farhadi, M.; Ale Ebrahim, N.A. comparison between two main academic literature collections: Web of Science and Scopus databases. Asian Soc. Sci. 2013, 9, 18-26. [CrossRef]

23. de la Cruz-Lovera, C.; Perea-Moreno, A.-J.; de la Cruz-Fernández, J.-L.; Alvarez-Bermejo, J.A.; Manzano-Agugliaro, F. Worldwide Research on Energy Efficiency and Sustainability in Public Buildings. Sustainability 2017, 9, 1294. [CrossRef]

24. Perea-Moreno, M.-A.; Hernandez-Escobedo, Q.; Perea-Moreno, A.-J. Renewable Energy in Urban Areas: Worldwide Research Trends. Energies 2018, 11, 577. [CrossRef]

25. Montoya, F.G.; Alcayde, A.; Baños, R.; Manzano-Agugliaro, F. A fast method for identifying worldwide scientific collaborations using the Scopus database. Telemat. Inform. 2018, 35, 168-185. [CrossRef]

26. JSON 2018. Available online: http:/ / www.json.org (accessed on 20 November 2018).

27. Franceschini, F.; Maisano, D.; Mastrogiacomo, L. Empirical analysis and classification of database errors in Scopus and Web of Science. J. Informetr. 2016, 10, 933-953. [CrossRef]

28. OpenRefine 2018. Available online: http:/ / openrefine.org/ (accessed on 20 November 2018).

29. Fortunato, S. Community detection in graphs. Phys. Rep. 2010, 486, 75-174. [CrossRef]

30. Yan, E.; Ding, Y.; Milojevic', S.; Sugimoto, C.R. Topics in dynamic research communities: An exploratory study for the field of information retrieval. J. Informetr. 2012, 6, 140-153. [CrossRef]

31. Newman, M.E. Scientific collaboration networks I. Netw. Constr. Fundam. Results Phys. Rev. E 2001, $64,016131$.

32. Kosmulski, M. The order in the lists of authors in multi-author papers revisited. J. Informetr. 2012, 6, 639-644. [CrossRef]

33. Regalado, A. Multiauthor papers on the rise. Science 1995, 268, 25. [CrossRef] [PubMed]

34. Newman, M.E.; Girvan, M. Finding and evaluating community structure in networks. Phys. Rev. E 2004, 69, 026113. [CrossRef] [PubMed]

35. Van Eck, N.J.; Waltman, L. CitNetExplorer: A new software tool for analyzing and visualizing citation networks. J. Informetr. 2014, 8, 802-823. [CrossRef]

36. Şener, S..E.C.; Sharp, J.L.; Anctil, A. Factors impacting diverging paths of renewable energy: A review. Renew. Sustain. Energy Rev. 2017, 81, 2335-2342. [CrossRef]

37. Hache, E.; Palle, A. Renewable energy source integration into power networks, research trends and policy implications: A bibliometric and research actors survey analysis. Energy Policy 2019, 124, 23-35. [CrossRef]

38. Engelken, M.; Römer, B.; Drescher, M.; Welpe, I.M.; Picot, A. Comparing drivers, barriers, and opportunities of business models for renewable energies: A review. Renew. Sustain. Energy Rev. 2016, 60, 795-809. [CrossRef]

39. Sequeira, T.N.; Santos, M.S. Renewable energy and politics: A systematic review and new evidence. J. Clean. Prod. 2018, 192, 553-568. [CrossRef] 
40. Bastian, M.; Heymann, S.; Jacomy, M. Gephi: An open source software for exploring and manipulating networks. In Proceedings of the Third International AAAI Conference on Weblogs and Social Media, San Jose, CA, USA, 17-20 May 2009.

41. Newman, M.E. Communities, modules and large-scale structure in networks. Nat. Phys. 2012, 8, $25-31$. [CrossRef] 